\title{
DISPOSITIVOS ESTRATÉGICOS DE DESIGN SOCIAL EM PROCESSOS DE CONSTRUÇÃO DE IDENTIDADE LOCAL
}

Dra. Anna Lúcia dos Santos Vieira e Silva Universidade Federal do Ceará annalucialilu@gmail.com

Dr. Emilio Augusto Gomes de Oliveira Universidade Federal do Ceará emiliodesign@gmail.com

Carlos Eugênio Moreira de Sousa Universidade Federal do Ceará eugeniomoreira@gmail.com
Filipe Garcia Macambira Universidade Federal do Ceará

f.macambira@yahoo.com.br

Lara Dias Monteiro Josino Universidade Federal do Ceará laradiasmj@gmail.com

Vitor Vieira Araújo Universidade Federal do Ceará Vtrara72@gmail.com

Resumo: A proposta desse artigo se fundamenta em uma pesquisa que busca analisar dispositivos estratégicos utilizados em projetos de design social, reconhecidos como métodos, técnicas e ferramentas (PAZMINO, 2015) capazes de ativar um processo de construção de identidade local, com os habitantes e usuários de espaços públicos que necessitam de regeneração. A partir dos fundamentos do design social e dos conceitos que envolvem a construção de lugar, a pesquisa investiga processos projetuais aplicados em situações reais onde comunidades informais, vulneráveis ou sem condições econômicas de contratar os serviços de escritórios de design e de arquitetura e urbanismo, solicitam auxílio para demandas específicas. Com o estudo de caso de um projeto no Varal Laboratório de Iniciativas em Design Social e o Canto - Escritório Modelo de Arquitetura e Urbanismo (EMAU), ambos da Universidade Federal do Ceará, são analisados os dispositivos estratégicos utilizados como a fotografia, peças gráficas, recursos digitais e artefatos. Por meio de metodologias colaborativas, como a pesquisa-ação (TRIPP, 2005; TOLEDO e JACOBI, 2013), e o design sistêmico (VEZZOLI e MANZINI, 2005) o projeto engloba diferentes níveis de agentes envolvidos no processo, como órgãos públicos municipais e estaduais, universidades públicas e privadas, escolas, associações de moradores e organizações não governamentais. Os dispositivos são aplicados em um cenário complexo, na organização das informações, no gerenciamento das ações, na divulgação do projeto com o objetivo de favorecer a construção de identidade local e construir a uma plataforma de referências, onde possam ser identificados e utilizados em futuros projetos de regeneração urbana.

Palavras chave: Design social; dispositivos estratégicos; identidade; espaço público; construção de lugar. 


\begin{abstract}
The purpose of this article is based on a research that aims to analyze strategic devices used in social design projects, recognized as methods, techniques and tools (PAZMINO, 2015) capable of activate a local identity construction process with the inhabitants and users of public spaces that require regeneration. From the foundations of social design and the concepts that involve space construction, the research investigates projectual processes applied in real situations in which communities that are informal, vulnerable or do not have an economic position to hire design, architecture and urbanism offices' services, request help for specific demands. With the case study of a project undertaken in Varal - Initiatives Laboratory in Social Design and Canto - architecture and urbanism's model office (EMAU), both from UFC federal University of Ceará, this article aims to analyze the strategic devices applied such as photography, graphic pieces, digital resources and artefacts. Through collaborative methodologies, like action-research and systemic design, the project cover different levels of agents involved in the process, such as municipal and state public agencies, public and private universities, schools, neighborhood associations and non-governmental organizations. The devices are implemented in a complex scenario, in the organization of information, management activities and project dissemination in order to promote the construction of local identity and build a platform of references, which can be identified and used in future urban regeneration projects. The devices are applied in a complex scenario, in the organization of information, management activities and project dissemination in order to promote the construction of local identity and build a platform of references, which can be identified and used in future urban regeneration projects.
\end{abstract}

Keywords: Social design; strategic devices; identities; public space; space construction.

\title{
1. INTRODUÇÃO
}

O que são dispositivos estratégicos em design social? Como podem ser empregados? Quais são os métodos, ferramentas e técnicas aplicados em propostas que implicam demandas de comunidades que não possuem recursos econômicos para contratar escritórios e profissionais de design, arquitetura e urbanismo? Qual é o papel do designer em projetos sociais interdisciplinares? Como resolver, por meio de recursos no âmbito do design, a construção do sentido de pertencimento de uma comunidade em relação ao local onde vive? A busca de respostas e soluções para essas questões fazem parte de uma pesquisa que teve início em 2015 , com o estudo das aplicações da fotografia em projetos de design social, no Varal - Laboratório de Iniciativas em Design Social, da Universidade Federal do Ceará (UFC).

Com o intuito de dar continuidade e aprofundamento à investigação, atualmente outros dispositivos estratégicos são identificados e analisados quando se apresentam capazes de promover a identidade local, o sentido de pertencimento e a autonomia de comunidades em processos de regeneração dos espaços públicos aos quais fazem parte. Nesse sentido, o presente artigo busca, a partir de definições e de conceitos, analisar suas aplicações em um projeto realizado, cujo foco principal é a fotografia, embora integre outros recursos e métodos utilizados no escopo da pesquisa. 
Em 2013 entidades do bairro Serrinha, em Fortaleza, afetadas diretamente por um problema local, buscam o Canto, Escritório Modelo de Arquitetura e Urbanismo (EMAU) da UFC, para transformar a situação. Depois de um diagnóstico participativo e de incorporar ao projeto outras instituições interessadas, o problema central foi identificado por um intenso processo de deterioração no espaço, localizado diante da escola pública de educação infantil Instituto Irmã Giuliana Galli, decorrente de habitações informais, com esgoto a céu aberto, depósito irregular de resíduos domésticos por parte da comunidade caracterizando um "lixão" e constantes alagamentos. Reconhecido o problema, o Canto se associa ao Varal e dão início ao "Projeto de transformação ativa Praça Ecológica Guaribal".

No escopo do projeto o objetivo é a regeneração e revitalização do local, para transformar o "lixão" em uma praça com a participação dos moradores em todas as etapas de criação, projeto e construção. Com isso, se realiza um processo sistêmico que envolve mutirões locais, mensais, que visam integrar os moradores e, primeiramente, conscientizá-los de que sua participação implica na efetiva transformação do espaço ao deixar o hábito de utilizá-lo como um depósito de lixo.

Para a transformação do espaço físico e social, a construção do sentido de pertencimento da comunidade em relação ao seu meio se mostra fundamental e, para realizá-la, são aplicadas metodologias colaborativas, especialmente a pesquisa-ação (TRIPP, 2005; TOLEDO e JACOBI, 2013) que agrega e implica a realidade prática nas investigações teóricas.

Diante disso, levanta-se a hipótese de que o Design Social quando aplicado em cenários que envolvem comunidades com problemas de degeneração urbana é capaz de desenvolver estratégias e dispositivos que auxiliam no processo de construção de lugar, que pode ser compreendido como a construção da identidade local.

\section{DESIGN E INOVAÇÃO SOCIAL, ESPAÇO PÚBLICO E CONSTRUÇÃO DE LUGAR}

O design tem suas bases reformuladas por ideias de estudiosos e designers, tais como Victor Papaneck, que em 1972, no lançamento do polêmico livro "Design for the Real World", traz uma forte crítica ao modelo tradicional de produção em série, fruto da revolução industrial, e aborda um novo conceito pautado no design voltado para as necessidades humanas, consciente dos impactos de seus produtos no meio ambiente. Através desse novo impulso, o design com foco no social passa a ganhar maior atenção por parte de outros designers e teóricos insatisfeitos com o modelo prioritariamente industrial. Krippendorff (2000) e Lobach (2001) abordam o Design Social como estratégia de dissolução de problemas que definem as pessoas de uma comunidade como os principais agentes, que agregam a sua cultura e ambiente o intuito de melhorar suas condições de vida. Estes autores atribuem responsabilidade social ao designer.

No prefácio do livro Metaprojeto: o design do design (MORAES, 2010), Ezio Manzini denomina como "próxima economia", uma nova fase do mundo contemporâneo, onde os bens de consumo não são a base da economia, em que o serviço orienta o produto e a economia de mercado divide espaço com a economia social. Manzini reafirma a ideia de que a economia de mercado não soluciona as dificuldades que surgem, nem sequer responde às demandas sociais. Assim, a próxima economia depende principalmente da inovação social. O termo inovação social (MANZINI, 2008) diz respeito a mudanças na forma como indivíduos ou comunidades 
agem para resolver seus problemas ou criam novas oportunidades, mais por meio de mudanças comportamentais do que por alterações tecnológicas ou de mercado. A inovação social e a diferenciação pelo design representam, assim, a mudança do escopo dos profissionais e a visível mudança no processo de absorção e valorização dos valores subjetivos, tidos anteriormente como fatores secundários (MORAES, 2010).

Processos organizacionais que emergem de demandas sociais podem ser descritos como um conjunto de atividades estruturadas e relacionadas com o foco em um produto ou serviço específico, como por exemplo, a necessidade de transformações comportamentais de uma comunidade em relação a seu espaço comum, o espaço público.

O papel do designer frente a inovação social, se encontra frequentemente relacionado a gestão de tarefas que constituem um conjunto de ações relacionadas entre si de forma lógica e coerente a fim de promover respostas favoráveis à problemática social observada. Neste contexto o designer atua com estratégias para soluções, como gestor na organização e articulação de informações complexas e como mediador entre os diferentes agentes envolvidos no projeto.

A implicação deste panorama que abrange os aspectos físicos, humanos e de uso da cidade são, juntamente com o design social, os parâmetros de fundamento da investigação proposta, na busca de dispositivos estratégicos do design capazes de promover a identidade local e a regeneração urbana.

O Design Social pressupõe uma abordagem diretamente vinculada a uma realidade ou localidade específica. Advém daí a necessidade do conceito de espaço público, entendido como o aspecto físico dos espaços de todos na cidade, como ruas e praças, calçadas, postes e muros, definidos desta forma por Henry Lefebvre (2008), Fabio Duarte (2002), Milton Santos (1997, 2001) e Otília Arantes (et. al. 2000).

Os fluxos urbanos, ou o espaço social, comunicativo, cultural e político, é tratado como esfera pública, definida a princípio por Jügen Habermas (2003), consagrada por filósofos e sociólogos como Hanna Arendt (1987), Richard Sennet (1998) e atualizada por pensadores contemporâneos como Rosalyn Deutsche (2001), Adrián Lavalle (2005) e Sérgio Abrahão (2008), como o ambiente da palavra, da ação, da opinião pública e da liberdade de expressão na sociedade.

Estes conceitos são relevantes para a inserção e definição dos espaços de atuação e da abrangência do design social em contextos ao mesmo tempo físicos, pragmáticos e sociais.

Duarte $(2002$, p.48) afirma que não há uma lógica absoluta do espaço, sequer uma lógica do espaço absoluto, e sim a de um espaço construído na relação entre objetos, ações e os seres humanos. O ser humano, entendido como agente de sua própria concepção do espaço, possibilita associações entre o design social e projetos de regeneração urbana, bem como a construção de identidade local.

Em uma abordagem mais objetiva, existem demandas onde a relação entre os objetos, as ações e os seres humanos de uma determinada localidade sofrem por uma falta de identidade e do sentido de pertencimento local. As consequências podem ser observadas em ações degenerativas no ambiente que repercutem negativamente na própria comunidade.

Fábio Duarte (2002, p.65) define lugar como: 
[...] uma porção de espaço significada, ou seja, cujos fixos e fluxos são atribuídos signos e valores que refletem a cultura de uma pessoa ou grupo. Essa significação é menos uma forma de se apossar desses elementos e mais de impregnálos culturalmente para que sirvam para a identificação da pessoa ou do grupo no espaço, para que encontrem a si mesmos refletidos em determinados objetos e ações e possam, assim, guiar-se, encontrar-se e construir sua medida cultural no espaço. (Duarte, 2002, p. 65)

Assim, o que diferencia um lugar de um espaço qualquer, é seu atributo de identidade, o sentido de pertencer e de fazer parte, o que indica a construção de lugar como um tipo específico de construção de identidade. Quando o foco é a construção de lugar em comunidades, o pensamento projetual é responsável por conceber, aplicar e otimizar dispositivos, recursos, técnicas e ferramentas que auxiliam na mudança de olhar da comunidade em relação a si e ao espaço que a circunda.

Cardoso (2012) propõe o olhar como uma construção sócio-cultural definida em uma especificidade local e histórica. Logo, esses dispositivos devem atingir, de forma direta, os fatores principais que constituem o espaço (objeto, ações e seres humanos), com o objetivo de transformar a equação que resulta do olhar, a concepção do lugar e o comportamento que o configura.

\section{DESIGN SOCIAL E A FOTOGRAFIA}

No "Projeto de transformação ativa Praça Ecológica Guaribal" uma pesquisa que implica a relação entre o design social e a fotografia se desenvolve, paralela e integrada às ações e intervenções propostas.

De acordo com Flusser (1985), há dois tipos de imagem: a tradicional e a técnica; a que, historicamente, precede o texto e a que o sucede, respectivamente. Após a aceitação da imagem fotográfica como "registro visual da verdade" (Sousa, 1997), a fotografia deixa de ser vista apenas como complemento do texto e ganha, ao longo do tempo e com os avanços tecnológicos, um papel de destaque que chega a substituí-lo.

Quando requisitada no âmbito da pesquisa, a imagem se torna instrumento de comunicação e documento de caráter científico, ou documentação fotográfica. Os registros fotográficos também podem fazer parte de um conjunto de documentos de processo (SALLES, 2011) que muitas vezes são utilizados no diagnóstico da situação trabalhada, na análise da eficácia dos procedimentos, ou para atingir um objetivo específico. Este documentos podem ter diferentes características e linguagens híbridas.

Em investigações que implicam o ambiente urbano, a cidade, o fotógrafo acrescenta às imagens seu ponto de vista crítico, o que exige uma aproximação ao objeto de estudo que costuma resultar em sua total imersão na situação investigada. A pesquisa-ação, por pressupor uma realidade prática a par e passo com a teoria é apropriada em ciclos de imersão seguidos de projetos laboratoriais acompanhados de aprofundamento teórico.

$\mathrm{Na}$ pesquisa, as características analíticas e reflexivas do projeto são empregadas como ferramenta na construção de um parâmetro de analise dos dispositivos estratégicos, tendo em vista promover interações entre diferentes 
discursos, linguagens e subjetividades, o que faculta uma natureza trans e interdisciplinar ao projeto.

Nos mutirões mensais do projeto analisado, o registro fotográfico garante as informações documentais e assume uma forma de envolvimento das pessoas da comunidade com os agentes envolvidos no processo. Os atores sociais integrados nas ações propostas, identificam o espaço e se reconhecem nas imagens como integrantes do processo, o que facilita uma reflexão crítica sua própria realidade e a construção conjunta de conhecimentos e habilidades, a ressignificação de valores e a transformação da situação problema. (TOLEDO, JACOBI, 2013)

Segundo Guran (2012), o documentarista que busca apreender o assunto que enfoca, produz fotografia de natureza exógena: imagens captadas por ele, como pesquisador, ou por sua equipe, sob a sua coordenação; as quais tentam responder as hipóteses levantadas no decorrer da pesquisa. Em contraste, há a fotografia de natureza endógena ou êmica, que difere da primeira por poder ou não estar sob o controle do fotógrafo. São fotografias feitas, principalmente, pelos membros do grupo social estudado, com uma fonte primária de informação, tradução das suas identidades, tanto individuais quanto coletivas. É importante ressaltar que uma fotografia pode mudar de natureza no curso da pesquisa. Além do potencial de expandir olhares à novas interpretações do que já foi constatado, tem um poder de significação próprio que lhe permite ser o ponto de partida de uma reflexão ou o resultado dela, mas nunca a reflexão em si, uma vez que é distintamente descritiva.

Aqui se reúnem fundamentos teóricos da investigação, onde a pesquisa-ação é aplicada para pesquisar a fotografia como objeto de documentação, registro, comunicação, fonte primária de informação e potencial propulsor no processo de construção de identidade local. Análogo ao documentarista, está o posicionamento de um designer no espaço que implica iniciativas em design social, uma vez que também requer completo envolvimento do profissional com o universo trabalhado. A convergência das duas atividades é relevante para o desempenho de ambas. Idealmente, a documentação fotográfica, em uma pesquisa de design social, é realizada por um designer com um "olhar fotográfico", para maior densidade, relevância e significação das imagens captadas, quando o designer-documentarista é treinado para identificar, nas duas esferas, os aspectos de maior destaque que possibilitam o desenvolvimento da pesquisa e do projeto.

\section{DISPOSITIVOS ESTRATÉGICOS, ESTUDO DE CASO}

O "Projeto de transformação ativa Praça Ecológica Guaribal", se desenvolve em um processo interdisciplinar de regeneração do espaço que, além da comunidade, envolve outros nove agentes: órgãos públicos municipais e estaduais, universidades públicas e privadas, escolas, associações de moradores e organizações não governamentais.

Por meio dos mencionados mutirões, o projeto prossegue com a colaboração dos diferentes grupos e em diversas áreas de atuação, como o projeto arquitetônico da praça, paisagismo e infraestrutura verde, conscientização e educação ambiental, proposta de soluções para descarte e coleta do lixo, equipamentos urbanos, lúdicos e mobiliários. Em todas as etapas do projeto e dos mutirões imersivos, são realizadas 
imagens fotográficas por diversos agentes, em especial, estudantes de design inseridos na pesquisa de design social e fotografia.

Além da captura das imagens, o grupo do design social se depara com demandas internas ao projeto, a saber: 1) organizar as ações, dado o nível de complexidade, abrangência e dinâmica do processo; 2) tornar a proposta compreensível no intuito de alcançar a própria comunidade e impulsionar sua participação; 3) divulgar os mutirões mensais; 4) conseguir parcerias no que tange serviços e espaços públicos junto aos órgãos municipais e estaduais; 5 ) propiciar a troca de saberes entre os envolvidos para o entendimento e possíveis ajustes do processo; 6) criar dispositivos capazes de gerar um sentido de pertencimento dos moradores em relação ao espaço público; 7) produzir um resumo do processo com especificação das necessidades materiais, para busca e obtenção de recursos;

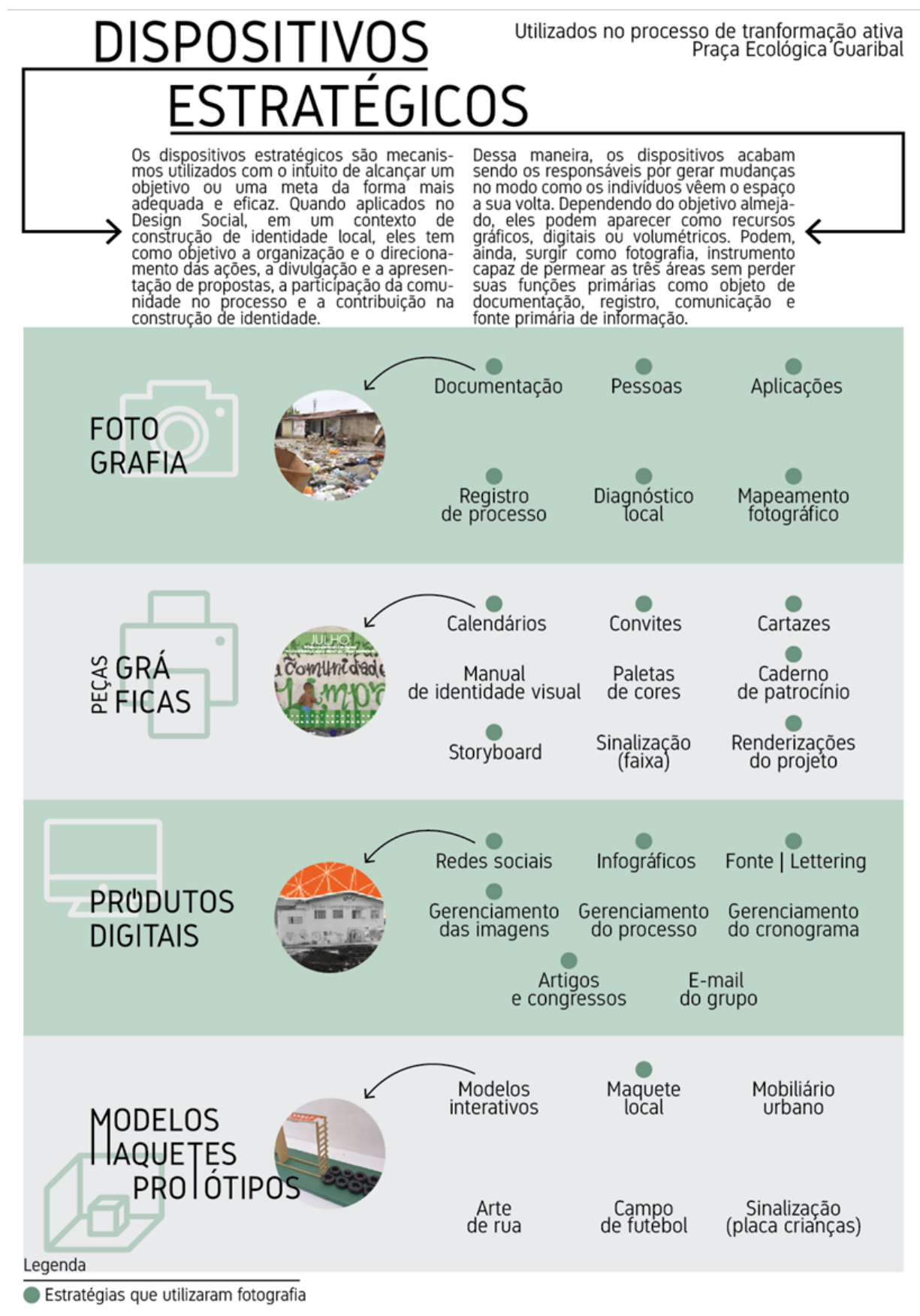

Imagem 1 - Infográfico dos dispositivos estratégicos aplicados. 
8) divulgar as ações e os conhecimentos que envolvem o projeto no âmbito acadêmico; 9) organizar o registro, o arquivo e a articulação das informações para uma futura publicação, capaz de propiciar referências para situações similares.

Para cada uma das demandas foram elaborados dispositivos estratégicos a partir de três parâmetros: recursos gráficos, digitais e artefatos, enquanto fotografia permeia os três.

Durante o processo, a fotografia se apresenta como um poderoso recurso de construção de identidade. O primeiro dispositivo estratégico aplicado ao projeto é uma sequencia de calendários divulgados mensalmente, em cada um dos mutirões, com as informações dos dias de coleta de lixo. Por meio do registro fotográfico dos moradores e das atividades relativas ao projeto e aos mutirões, é eleita uma das fotos que seja representativa do mês, aplicada ao calendário do mês seguinte. Assim, em cada mutirão os calendários são distribuídos. Para sua elaboração é solicitado o preenchimento de autorização de uso da imagem, a partir das fotos realizadas. Como efeito, as pessoas se reconhecem na imagem, passam a aderir aos encontros e a se interessar pelo projeto, uma vez que estão integradas nele.
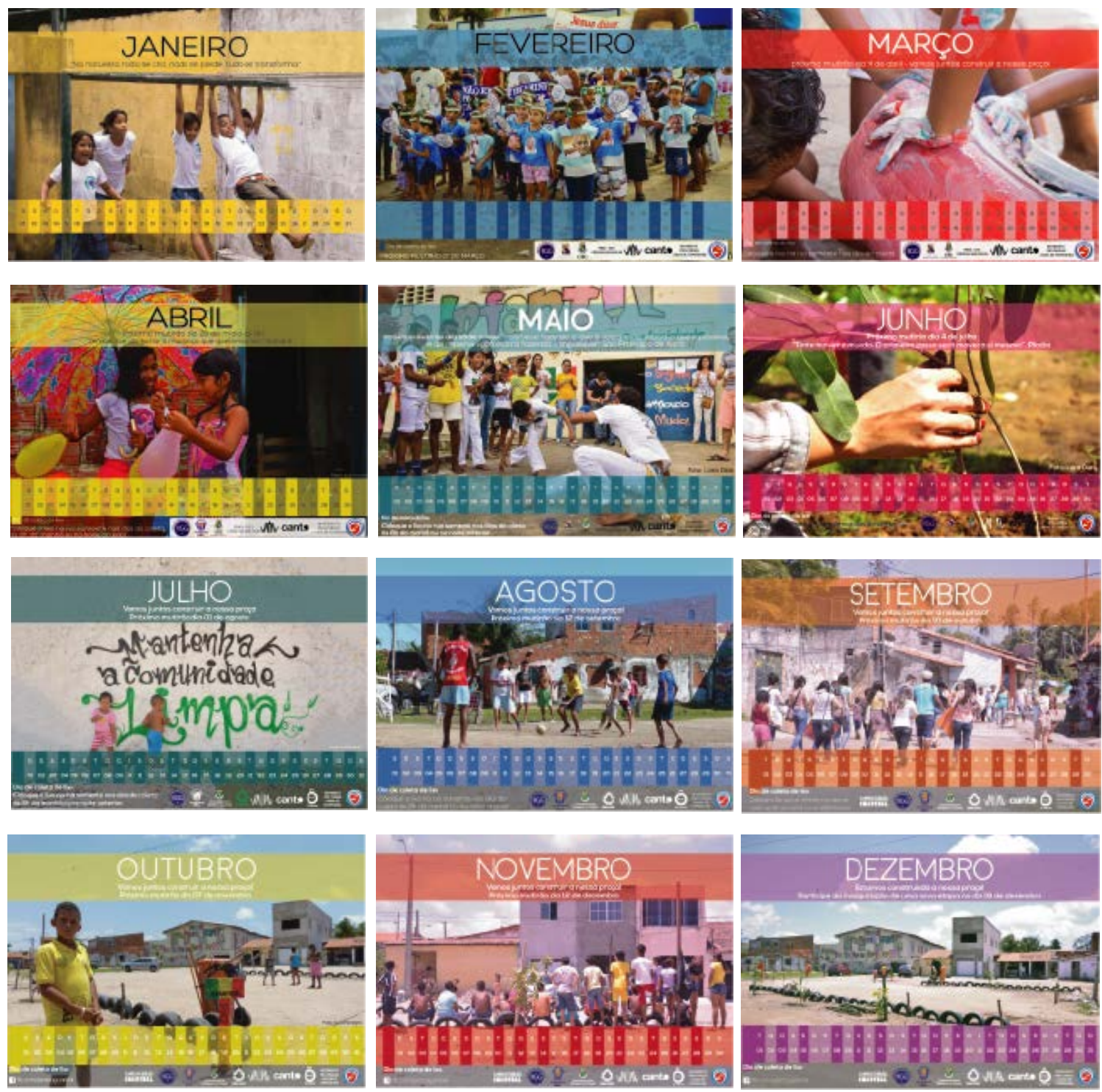

Imagem 4 - Calendários do "Projeto de transformação ativa Praça Ecológica Guaribal”. 
As metodologias se inserem de forma ampla no cenário projetual, onde se pressupõe a presença de no mínimo duas abordagens: uma preliminar, responsável pela criação de uma plataforma de conhecimentos que servirá de guia durante o processo projetual, o metaprojeto (MORAES, 2010). Outra, a pesquisa-ação (TRIPP, 2005; TOLEDO e JACOBI, 2013), é aplicada como base teórico-metodológica na busca do aprimoramento contínuo da prática das intervenções participativas, colaborativas e co-criativas, em ciclos de imersão na comunidade alternados por trabalhos de propostas de análise e novas perspectivas de intervenção, que são implantadas nas subsequentes imersões em um processo sucessivo e progressivo. Assim, as demandas do processo são indicativas da necessidade de criação de outros dispositivos, que são realizados e variam de acordo com a estratégia e necessidade, em um sistema aberto que facilita a possibilidade de diferentes rumos no processo, em função das demandas encontradas. (TOLEDO, JACOBI, 2013, p. 159-160)
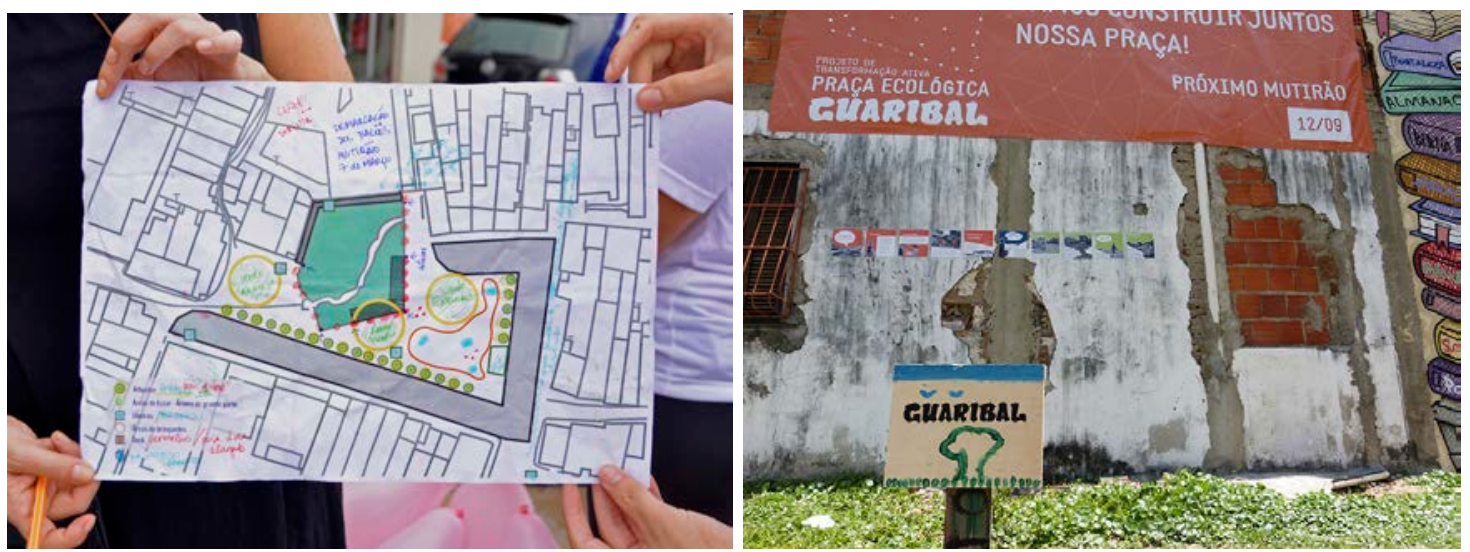

Imagem 5 - Sequencia de dispositivos estratégicos aplicados durante o processo. Projeto utilizado no mutirão de abril de 2015 para marcação dos elementos na praça. Elaboradas pelos autores, com base na pesquisa realizada.

Imagem 6 - Banner de indicação das datas dos mutirões e placa de identificação de muda realizada por crianças no mutirão de agosto. Elaboradas pelos autores, com base na pesquisa realizada.

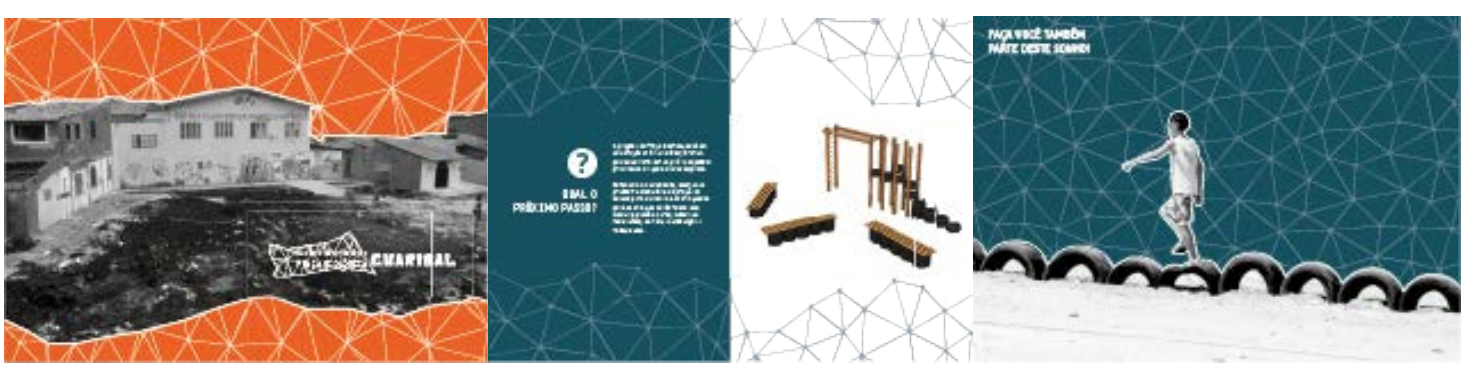

Imagem 7, 8 e 9 - Imagens do caderno de patrocínio. Elaboradas pelos autores, com base na pesquisa realizada. 


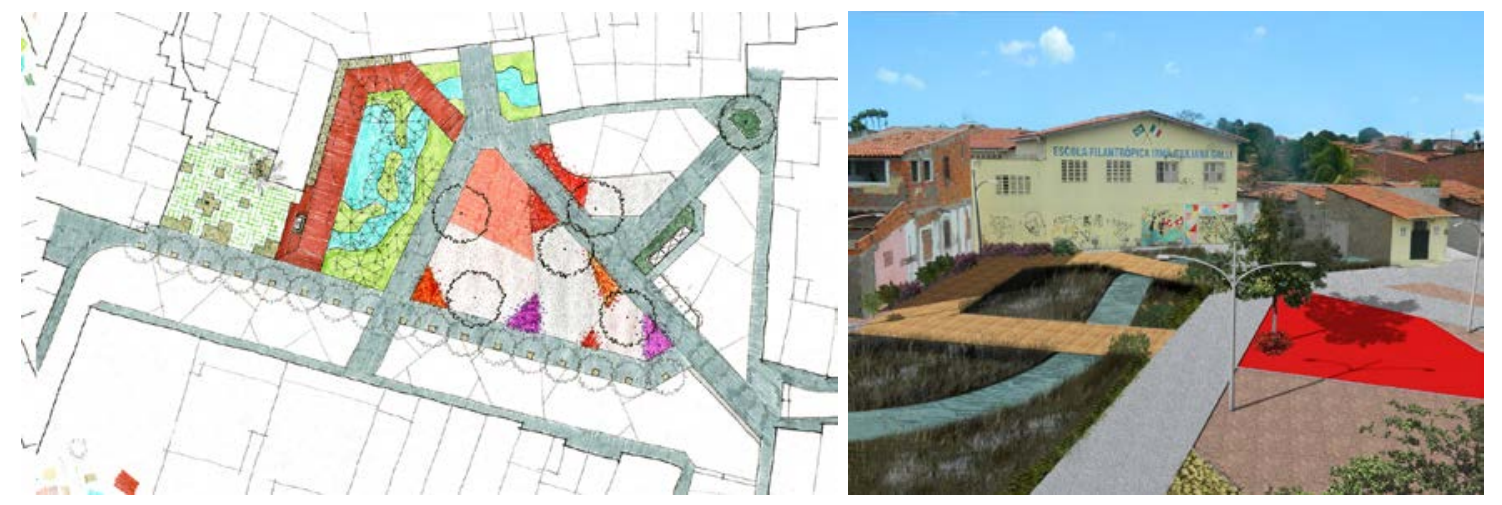

Imagens 10 e 11 - etapas do projeto utilizadas em apresentações. Elaboradas pelos autores, com base na pesquisa realizada.

Busca-se, com uma observação sistemática do processo, uma compreensão dos dispositivos estratégicos e suas implicações, a partir dos resultados materiais obtidos por meio de registros concretos de suas consequências. São métodos que se tornam produtos das articulações que o designer opera entre os seus conhecimentos técnicos, suas vivências cotidianas e as dinâmicas empreendidas nos espaços urbanos e sociais trabalhados, com as especificidades culturais e comunitárias.

O recurso das imagens fotográficas e outros registros, permite avaliar os procedimentos aplicados, seus resultados no espaço e no comportamento das pessoas envolvidas, especialmente os moradores da comunidade.

No decorrer do ano, os dispositivos foram empregados das mais variadas maneiras para a obtenção do resultado proposto: a transformação do "lixão" em uma praça. No início do processo, registros do que poderia vir a ser o local e, em seguida, como essa transformação poderia ser realizada.

A maior dificuldade na primeira metade do ano foi a de construir o reconhecimento de que não seriam a universidade ou qualquer outro agente envolvido no projeto os responsáveis pela transformação, e que esta não se realizaria sem a adesão da comunidade para romper com o hábito de descarte dos resíduos domésticos. No quinto mutirão, programado no evento do dia das mães em maio, a renderização das imagens no projeto e sua inserção em fotos do local foram aplicadas com o chamado "Vamos construir a nossa praça!". A adesão e compreensão de que a união é necessária para a realização da praça pareceu unânime. O mutirão seguinte, em junho, é considerado um ponto de inflexão, dado pela a própria comunidade que, com seu empoderamento, se organiza para limpeza do lugar e implanta um campo de futebol para as crianças sobre o espaço onde anteriormente havia o maior acúmulo de lixo. O muro é grafitado com os dizeres "Guaribal e Favela na paz de Deus" e "Mantenha a Comunidade limpa", também por iniciativa deles.

Com a atuação dos moradores como participantes ativos na construção da praça, o sentido de pertencimento e consequente identidade do local é assimilado ao projeto. Nos meses seguintes, com o projeto reconhecido como vitorioso por todas as partes interessadas, a continuidade do processo passa a ser a qualificação do espaço por meio de plantação de mudas, construção de equipamentos, mobiliários, busca de patrocínio e parcerias com órgão públicos para as transformações de infraestrutura, saneamento e drenagem. 


\section{CONCLUSÃO}

Rosalyn Deutsche (2001) apresenta o espaço público como um ambiente de atividade política e por meio desta definição discute a esfera pública como uma interação discursiva, onde os indivíduos assumem identidades políticas. Por outro lado, uma razão pela qual não existe muito suporte a serviços de design social é o escasso número de pesquisas que demonstrem como um designer pode contribuir para o bem-estar humano (MARGOLIN, 2004). Partindo dessas duas premissas, é levantada a hipótese de que a participação ativa das comunidades com as quais se coopera é essencial em propostas de transformação do espaço comum, para que os resultados alcancem um nível de sustentabilidade urbana e social aceitável. Assim se pode verificar a eficácia dos métodos e analisar os processos a partir de suas consequências.

Ao incorporar a necessidade dos diferentes saberes inerentes a todos os envolvidos com o projeto, que devem se encontrar na mesma posição, horizontal, de troca de experiências, de conhecimentos e de busca de soluções, Krippendorff atualiza a ação do Design Social: "O design gera um entendimento de segunda ordem da capacidade que os outros tem de projetar seus próprios mundos" (KRIPPENDORFF 2000, p. 91). Para isso, é preciso um passo anterior em que os dispositivos do design precisam atuar: gerar o entendimento da comunidade do problema que ela mesma sofre para, assim, assumir a corresponsabilidade por sua dissolução.

Uma vez comprometida com a solução do problema, a comunidade ganha um novo patamar de autonomia e pode dar continuidade às transformações no espaço ao qual pertence, que passa a ser seu de uma forma diferente, mais consciente. Assim, na união de aspectos materiais e processuais, pode-se afirmar que em projetos como este, métodos, técnicas e ferramentas são criados a partir dos significados que o designer atribui e interpreta no processo, em propostas e construções compartilhadas com todos os envolvidos no projeto, dentro de um amplo objetivo comum.

\section{REFERÊNCIAS}

ABRAHÃO, S. L. Espaço público: do urbano ao político. São Paulo: Annablume; Fapesp, 2008.

ARANTES, Otília; VAINER, Carlos; MARICATO, Ermínia. A Cidade do Pensamento Único. Desmanchando consensos. Petrópolis, Rio de Janeiro: Vozes, 2000.

BARBIÈR, Renè. A Pesquisa Ação. Tradução Lucie Didio. Brasília: Libel Livros, 2007.

BRAGA, Marcos da Costa (org.). O Papel Social do Design Gráfico. História, conceitos \& atuação profissional. São Paulo: Senac, 2011.

BONSIEPE, Gui. Design como prática de projeto. São Paulo: Blucher, 2012.

. Design, Cultura e Sociedade. São Paulo: Blucher, 2011.

BORJA, J.; MUXI, Z. El Espacio Público: ciudad y ciudadanía. Barcelona: Electra, 2003.

CARDOSO, Rafael. Design para um mundo complexo. São Paulo: Cosac Naify, 2012.

DEUTSCHE, Rosalyn. Agorafobía. In BLANCO, P - CARRILLO, Jesus - CLARAMONTE, J DUBOIS, P. $O$ acto fotográfico. Lisboa: Vega, 1991. 
EXPÓSITO, M. Modos de Hacer. Arte Crítico, Esfera Pública y Acción Directa.

Salamanca: Universidad de Salamanca, 2001, p. 308-309.

GURAN, M. Documentação fotográfica e pesquisa científica: notas e reflexões. XII Prêmio Funarte Marc Ferrez de Fotografia, 2012.

GURAN, M. Considerações sobre a constituição e a utilização de um corpus fotográfico na pesquisa antropológica. Discursos Fotográficos, Londrina, v7, n10, p. 77-106, jan/jun, 2011.

DUARTE, F. Crise das matrizes espaciais: arquitetura, cidades, geopolítica e tecnocultura. São Paulo: Perspectiva, 2002.

FERRARA, Lucrécia D’Alessio. Design em Espaços. São Paulo: Rosari, 2002.

FLUSSER, Vilém. Filosofia da caixa preta: ensaios para uma futura filosofia da fotografia. Rio de Janeiro: Relume Dumará, 2002.

HABERMAS, Jürgen. Mudança Estrutural da Esfera Pública: Investigações quanto a uma categoria da sociedade burguesa. Trad. Flávio Kothe. Rio de Janeiro: Tempo Brasileiro, 2003.

JOLY, Martine. Introdução à Análise da Imagem, Lisboa, Ed. 70, 2007.

KRIPPENDORFF, Klaus. Design centrado no ser humano: uma necessidade cultural. Tradução Gabrielle Meireles. Estudos em Design, Rio de Janeiro: Associação de Ensino de Design do Brasil, v. 8, n. 3, p. 87-98, setembro de 2000.

LAVALLE, A. G. Espaço e vida públicos: reflexões teóricas e sobre o pensamento brasileiro. São Paulo: Universidade de São Paulo; Faculdade de Filosofia, Letras e Ciências Humanas, 2001.

LAWSON, Bryan. Como Arquitetos e Designers Pensam. Tradução Maria Beatriz Medina. São Paulo: Oficina de Textos, 2011.

LEFEBVRE, Henri. A Revolução Urbana. Tradução Sérgio Martins. Belo Horizonte: UFMG, 2008.

LÖBACH, B. Design industrial: bases para a configuração dos produtos industriais. São Paulo: Edgar Blusher, 2001.

MANZINI, E.; Tradução: Carla Cipolla. Design para a inovação social e sustentabilidade: comunidades criativas, organizações colaborativas e novas redes projetuais. Rio de Janeiro: E-papers, 2008.

MANZINI, Ezio; VEZZOLI, Carlo. O Desenvolvimento de Produtos Sustentáveis: os requisitos ambientais dos produtos industriais. Trad. Astrid de Carvalho. São Paulo: EDUSP, 2005.

MARGOLIN, Victor; MARGOLIN, Sylvia. Um “Modelo Social de Design": questões de prática e pesquisa. Trad. Paulo Fernando de Almeida Souza. Revista Design em Foco, Salvador, v.1, n.1, p. 43-48, julho/dezembro. 2004.

MORAES, Dijon. Metaprojeto: o design do design. São Paulo: Blucher, 2010. 
NOJIMA, Vera; ALMEIDA JR, Licínio; RIBEIRO, Adriana B. Um plano metodológico para um projeto de pesquisa em design. Estudo e prática de metodologia em design nos cursos de pós-graduação. Rio de Janeiro: Novas Ideias, 2011.

NORMAN, Donald. Design do dia a dia. Rio de Janeiro: Rocco, 2006.

PAPANEK, Victor J. Design for the Real World. Thames and Hudson. Universidade da Califórnia, 1972.

PAZMINO, A. V. Como se Cria: $\mathbf{4 0}$ métodos para design de produto. São Paulo: Blucher, 2013.

PIRES, J. B.; CONTANI. M. L. Imagem física e qualidade mental: a fotografia vista pela semiótica. Discursos Fotográficos, v1, p. 167-182, 2005.

POL, Enric. Cognición, representación y apropiación del espacio. Barcelona: Universidad de Barcelona, 1996.

SANTOS, Milton. A Natureza do Espaço: técnica e tempo, razão e emoção. São Paulo: Hucitec, 1997.

. Por uma outra globalização: Do pensamento único à consciência universal. Rio de Janeiro: Record, 2001.

SALLES, Cecília A. Gesto Inacabado: processo de criação artística. São Paulo: Intermeios, 2011. 